\title{
Growth and Analysis of Urea Thiourea Sodium Sulphate Crystal
}

\author{
Palanisamy Saritha ${ }^{1}$, Seshathri Barathan ${ }^{2}$, Ganesan Sivakumar ${ }^{3}$ \\ ${ }^{1}$ (Engineering Physics Section, Annamalai University, Annamalai nagar-608002, India) \\ ${ }^{2}$ (Department of Physics, Annamalai University, Annamalai nagar -608002, India) \\ ${ }^{3}$ (CISL, Department of Physics, Annamalai University, Annamalai nagar -608002, India)
}

\begin{abstract}
Urea Thiourea Sodium sulphate (UTNS) crystal have been grown from aqueous solution by slow evaporation technique at room temperature. The crystal structure was confirmed by powder XRD technique and it reveals that UTNS crystal belongs to orthorhombic system. Microstructure and compositions of the grown single crystal UTNS was carried out by SEM with EDS. The molecular structures present in the crystal were identified by recording the FTIR spectrum. Optical property was established by UV-Visible spectrum and the mechanical strength of the grown crystal was estimated by the Vicker's microhardness test.
\end{abstract}

Keywords: FT-IR, Microhardness, Powder XRD, SEM, Slow evaporation.

\section{Introduction}

Highly efficient nonlinear optical (NLO) materials with good mechanical strength and chemical stability are essentially required for optoelectronic applications such as optical communications, high speed information processing, optical switches, optical frequency conversion and optical data storage $[1,2]$. Materials with second-order optical nonlinearities, short transparency lower cut-off wavelength and high thermal and mechanical properties are the essentialities for the realization of many of these applications [3].

Urea $\left(\left(\mathrm{NH}_{2}\right)_{2} \mathrm{CO}\right)$ is a good organic nonlinear crystal. It is a useful material for high power laser frequency shifting in a wide spectral range, because of its large transparency window, large birefringence, relatively high damage threshold and low temperature dependence of the refractive indices. In combination with aldehydes it can be made into plastics and resins and is used extensively in the paper industry to soften cellulose fibers. The molecule has two- $\mathrm{NH}_{2}$ groups joined by a carbonyl $(\mathrm{C}=\mathrm{O})$ functional group [4].

The thiourea molecule is an interesting inorganic matrix modifier due to its large dipole moment and ability to form extensive network hydrogen bonds [5]. Thiourea $\left(\mathrm{CH}_{4} \mathrm{~N}_{2} \mathrm{~S}\right)$ consists of white solid which crystallizes in an orthorhombic structure. Thiourea crystals also exhibit piezoelectric effect, which is utilized in ultraviolet (UV), infrared (IR), scanning electron microscopy (SEM) detection and imaging. Semi organic NLO crystals are expected to possess the advantages of both inorganic and organic materials. Sodium sulfate is a white crystalline solid of formula $\mathrm{Na}_{2} \mathrm{SO}_{4}$ known as the mineral thenardite; the decahydrate $\mathrm{Na}_{2} \mathrm{SO}_{4}{ }_{10} \mathrm{H}_{2} \mathrm{O}$ is found naturally as the mineral mirabilite, and in processed form has been known as Glauber's salt and orthorhombic or hexagonal crystal structure [6].

The objective of the research for which results are reported below, was to determine the combined effects of urea, thiourea and sodium ions on the structural behavior of UTNS crystal formation, XRD to study their crystallographic structure, FTIR to identify their molecular structures and using SEM to analyze the microstructures.

\section{Synthesis and Crystal growth}

\section{Materials And Methods}

The slow evaporation technique was used to grow a single crystal of UTNS in aqueous solution. UTNS salt was synthesized by dissolving urea, thiourea and sodium sulphate in a molar ratio 1:3:3 in double distilled water. The calculated amount of urea thiourea reacts with sodium sulphate salt was dissolved in double distilled water by mixed thoroughly using a magnetic stirrer. The solution was constantly stirred well for $6 \mathrm{hrs}$ till the saturated and homogenous solution was achieved. Then the solution was filtered by whattman filter paper and left undisturbed for slow evaporation at room temperature. The purity of the synthesized salt was improved by successive recrystallization. Well developed, a good transparent crystal of size $12 \times 12 \times 4 \mathrm{~mm}^{3}$ was harvested in a growth period of 25-30 days and is shown in Fig.1. 


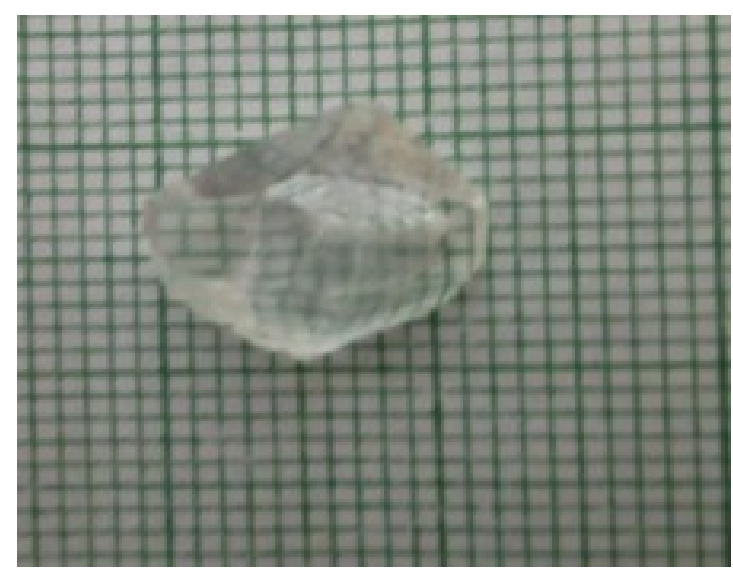

Fig.1.Photograph of UTNS Crystal

\section{Results And Discussions}

\subsection{Powder $X$-Ray diffraction analysis}

The grown crystal was subjected to powder X-ray diffraction analysis using diffraction system XPERT -PRO with $\mathrm{Cu} \mathrm{K}$ alpha radiation $(\lambda=1.54060 \AA)$. The powdered sample was scanned over the range $(2 \theta)$ 10 to $80^{\circ}$. The reflection peaks corresponding to different crystal planes in XRD spectrum were indexed (Fig.2.). The obtained XRD pattern was analyzed by PROSZKI software package [7]. The results suggest that the crystal belongs to orthorhombic system. The sharp and well defined peaks confirm the good crystalline of the grown crystal.

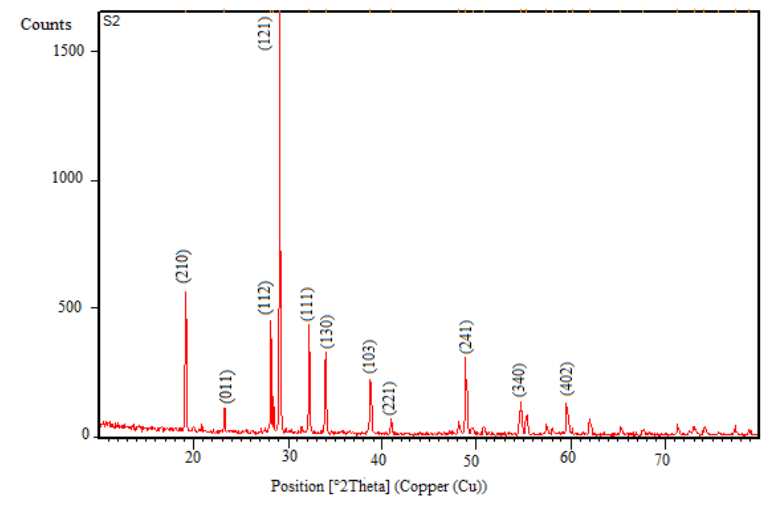

Fig.2.XRD analysis of UTNS Crystal

\subsection{FTIR spectrum analysis}

In order to analyze the grown crystal qualitatively for the presences of functional groups were identified by the FT-IR spectrum was recorded between $4000-400 \mathrm{~cm}^{-1}$ using Perkin Elmer RX1 FT-IR spectrometer, by KBr pellet technique. The FTIR spectrum of UTNS crystal is shown in Fig.3.

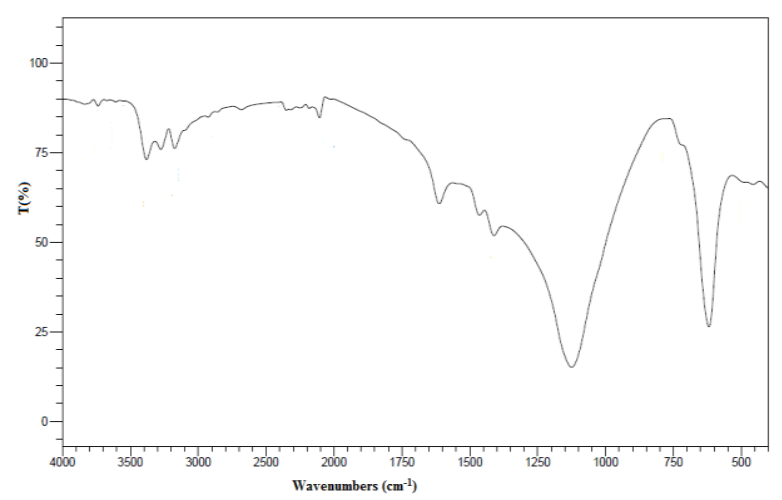

Fig.3.FT-IR spectrum of UTNS Crystal

The strong absorption bands in the region $3170-3390 \mathrm{~cm}^{-1}$ corresponds to symmetric and asymmetric stretching vibration of $\mathrm{NH}_{2}$ group of thiourea [8, 9].The band at $1612 \mathrm{~cm}^{-1}$ may be attributed to $\mathrm{NH}_{2}$ bending of 
scissors vibration. The single band structure at $1463 \mathrm{~cm}^{-1}$ is due to asymmetric stretching vibrations of N-C-N. The band at $1124 \mathrm{~cm}^{-1}$ is assigned to bending (rocking) vibration of $\mathrm{NH}_{2}$. The $\mathrm{C}=\mathrm{S}$ asymmetric stretching vibration is observed at $1411 \mathrm{~cm}^{-1}$ and the symmetric stretching vibration of $\mathrm{C}=\mathrm{S}$ band at $720 \mathrm{~cm}^{-1}$ respectively $[10,11]$. The strong band at $619 \mathrm{~cm}^{-1}$ is due to rocking vibration of C-H bond. Small band at $489 \mathrm{~cm}^{-1}$ is attributed to the bending vibration of N-C-S molecules.

\subsection{Optical transmission spectrum analysis}

UV-Visible spectral studies is a useful tools determine the transparency which an important requirement for a material to be optically active. The optical transmission spectrum of UTNS was recorded in the range $200-1100 \mathrm{~nm}$ using Shimadzu -UV 1800 spectrometer. The plot of transmittance (\%) vs. wavelength $(\mathrm{nm})$ is shown in Fig.4. There is no absorption band between 300 and $1100 \mathrm{~nm}$. The sample has a good transmittance and the lower cut off wavelength lies below $300 \mathrm{~nm}$ and is almost equal to thiourea. The material is found to be transparent to all radiations in the wavelength range $300-1100 \mathrm{~nm}$. The absence of absorption in the visible region clearly indicates that UTNS can be used as a window material in Optical instruments [12].

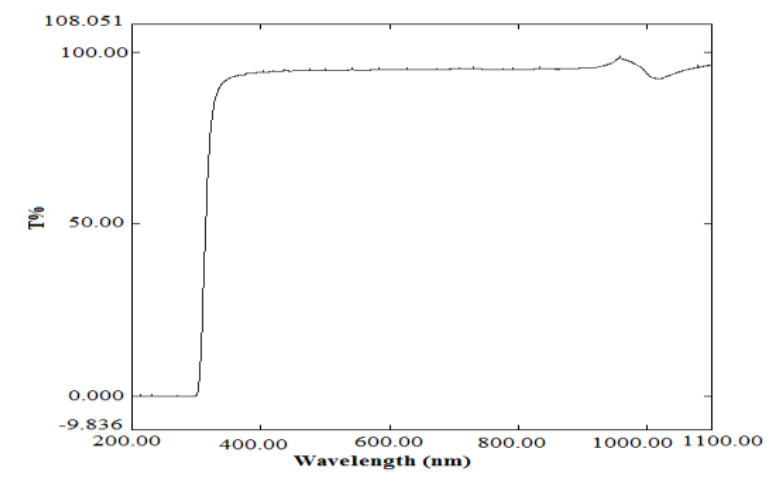

Fig.4.UV-vis spectrum of UTNS

\subsection{Mechanical strength studies}

The mechanical strength of the crystal was made by Vickers's microhardness test at room temperature. Observations of the various indentations test were done using the Metallux-II Metallurgical Microscope. Vickers's microhardness study for UTNS crystal is performed on polished smooth surface of the crystal with different loads like $10 \mathrm{~g}, 20 \mathrm{~g}, 30 \mathrm{~g}, 40 \mathrm{~g}, 50 \mathrm{~g}, 60 \mathrm{~g}$ and $70 \mathrm{~g}$. The maximum load is restricted to above $60 \mathrm{~g}$ as micro cracks were developed at higher loads. The Hardness numbers of the grown crystal was calculated using the relation, $\mathrm{H}_{\mathrm{V}}=1.8544 \mathrm{P} / \mathrm{d}^{2} \mathrm{~kg} \cdot \mathrm{mm}^{-2}$. Where $\mathrm{P}$ is the applied load in $\mathrm{kg}, \mathrm{d}$ is the average diagonal length in $\mathrm{mm}$ of the indentation impression. Hardness number of the crystal increases gradually with increase in load.

$\mathrm{H}_{\mathrm{V}}$ value increases up to a load of $60 \mathrm{~g}$. Cracks develop around the indentation mark above the load of $60 \mathrm{~g}$. This indicates that UTNS crystal has a high VHN value comparable with other organic NLO as well as semi organic NLO crystals [13].

\subsection{SEM with EDS analysis}

SEM analysis provided information's about the nature, suitability for device fabrications and also it is used to check the presence of imperfections. SEM analysis was carried out using JEOL JSM-5610 LV Scanning Electron Microscope with an accelerating voltage of $20 \mathrm{kV}$, at high vacuum mode and secondary electron image (SEI). Since semi organic crystals are non-conducting in nature, gold coating (JEOL auto fine Coater JFS-1600) was done for $120 \mathrm{~s}$ before subjecting the UTNS crystal surface to electron beam [14]. UTNS crystal has well developed morphology with several habit faces (Fig. 5a). It exhibiting layered growth and it is observed that the basic units are arranged in different layers, which is a clear evidence for the stacking of fundamental units during crystal growth. UTNS crystal was also analyzed by energy dispersive spectroscopy (EDS) for qualitative and quantitative information and is shown in figure.5b. From the EDS spectra $\mathrm{Na}$ and $\mathrm{S}$ doped are present in the UTNS crystal. 


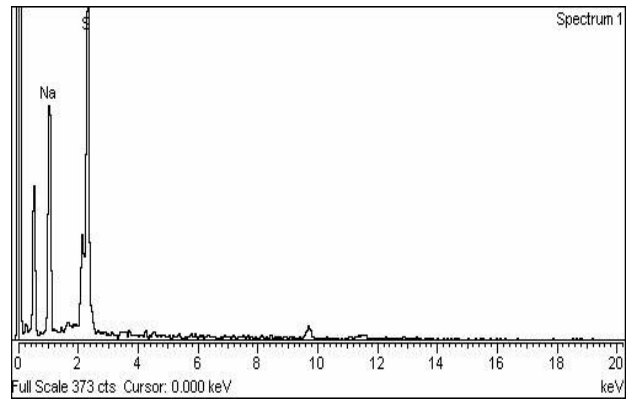

Fig.5a. SEM image of UTNS Crystal

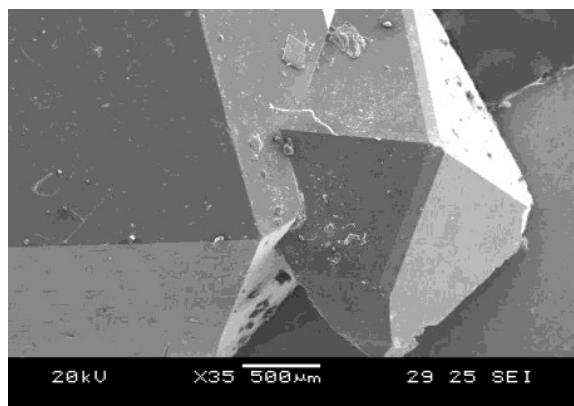

Fig. 5b. EDS spectrum of UTNS Crystal

\section{Conclusions}

Good quality of a new single crystal of UTNS was grown by the slow evaporation method at room temperature. The crystal is confirmed with Powder XRD analysis and it belongs to the orthorhombic system. The surface morphology and some elemental compositions of the crystal were reported by SEM with EDS analysis. The FT-IR spectral analysis identified the presences of functional groups. The $\mathrm{C}=\mathrm{S}$ asymmetric and symmetric stretching vibrations of UTNS crystal were observed at 1411 and $720 \mathrm{~cm}^{-1}$. The UV-Vis spectra showed that the crystal had a wide optical window, no absorbance and good optical transmittances in the entire visible region. Microhardness Test reveals that the UTNS crystal possesses moderate hard nature.

\section{References}

[1] V.G. Dimitriev, G.G. Gurzadyan, D.N. Nicogosyan, Hand book of Nonlinear Optical Crystals, (New York : Springer-Verlag),1999.

[2] M.S. Wong, C. Bosshard, F.Pa. P. Gunter, "Non-classical donor-acceptor chromophores for Second Order Nonlinear Optics" Advanced Material, 8, 1996, 677-680.

[3] S. Gopinath, S. Barathan, R. Rajasekaran, Comparative Study of Thiuorea Metal Complexes Crystals, Advanced Materials Research, 584, 2012, 112-115.

[4] X.Q. Wangg, D. Xu, D.R. Yuan, Y.P. Tian, W.T. Yu, S.Y. Sun, Z.H. Yang, Q. Fang, M.K. Lu, Y.X. Yan, F.Q. Meng, S.Y. Guo, G.H. Zang and M.H. Jiang, Synthesis, structure and properties of a new nonlinear optical material, Materials Research Bulletin, 34, 1999, 2003-2011.

[5] D. Andreeti, L. Cavalca and A. Musatti, Electro-optic, piezoelectric, and dielectric properties of zinc tris thiourea sulfate, Acta crystallographica B, 24, 1968, 683 .

[6] A. Henri, C. Levy and Georoe, Lisensky, Crystal Structures of Sodium Sulfate Decahydrate (Glauber's Salt) and Sodium Tetraborate Decahydrate (Borax). Redetermination by Neutron Diffraction, Acta CrystalographicaB, 34, 1978, 3502-3510.

[7] XU. JiXiang, Fangyan, Fange Chunhui, Structure of aqueous sodium sulfate solutions derived from X-ray diffraction, Chinese Science Bulletin, S4, 2009, 2022-2027.

[8] P.M. Ushasree, R. Muralidharan, R. Jayavel, P. Ramasamy, Growth of bis thiourea cadmium Chloride single crystals, Journal of Crystal Growth, 218, 2008, 365-371.

[9] S. Gopinath, S. Barathan, R. Rajasekaran, Growth and characterization of semi-organic nonlinear optical crystal, Journal of Pure and Applied Science and Technology, 21, 2012, 27-33.

[10] G. Madhurambal, M. Mariappan, S.C. Mojumdar, TG/DTA, UV and FTIR spectral studies of urea-thiourea mixed crystals, Journal of Thermal Analysis Calorimetry, 100, 2010, 853-856.

[11] A. Ruby, S. Alfred Cecil Raj, Growth, Spectral, optical and thermal characterization of NLO organic crystal - Glycine thiourea, International Journal of Chem Tech Research, 5, 2013, 482-490.

[12] S. Kumararaman, I. Cicili Ignatius, T. Thaila, T. Raja, K. Selvaraju, Growth, spectroscopic, thermal and hardness studies of urea thiourea zinc iodide crystal as potential NLO material, Archives of Applied Science Research, 4, 2012, $2467-2473$.

[13] S. Nalini Jayanthi, A.R. Prabhakaran, D. Subashini, K. Thamizharasan, Growth and characterization of a non-linear optical crystal, International Journal of Advances in Engineering \& Engineering \& Technology, 5, 2013, 85-92.

[14] G. Sivakumar, Md.R. Ahamed, S. Partiban, SP. Meenachisundaram, S.C. Mojumdar, The effect of Co ${ }^{2+}-\mathrm{Doping}$ on Tetra (Thiourea) Copper (I) Chloride crystals, Journal of Thermal Analysis Calorimetry, 94, 2008, 53-57. 